\title{
El videojuego como forma de memoria estética ${ }^{1}$ Video games as a form of aesthetic memory
}

\author{
Alberto Venegas Ramos \\ Universidad de Murcia \\ alberto.venegasr@um.es \\ ORCID: 0000-0002-5621-7749
}

Recibido: 21-8-19

Aceptado: 11-11-19

Cómo citar este artículo / Citation: VENEGAS RAMOS, Alberto (2020). El videojuego como forma de memoria estética. Pasado y Memoria. Revista de Historia Contemporánea, 20, pp. 277-301

https://doi.org/10.14198/PASADO2020.20.12

\section{Resumen}

El presente trabajo examina el videojuego histórico como una forma de memoria estética. A través del estudio de distintos títulos recientes y populares ambientados en el pasado, como Call of Duty: WWII (Sledgehammer Games, 2017) y Battlefield V (DICE, 2018) tratamos de definir e ilustrar el concepto de "memoria estética". Se trata de un concepto entendido como la reproducción de imágenes definitorias y populares de un momento histórico. Se trata de imágenes seleccionadas por distintos grupos sociales, alejados del oficio del historiador, cuya función es consolidar la verosimilitud histórica del producto y que son consideradas canónicas y representativas de un momento concreto.

Palabras clave: Historia. Usos públicos de la Historia. Memoria. Estética. Videojuegos. Arte de consumo de masas.

1 Este trabajo ha sido realizado en el marco del proyecto de investigación "Historia y videojuegos (II): conocimiento, aprendizaje y proyección del pasado en la sociedad digital" (HAR2016-78147-P). 


\begin{abstract}
This paper examines the historical video game as a form of aesthetic memory. Through the study of recent and well-known different titles set in the past, such as Call of Duty: WWII (Sledgehammer Games, 2017) and Battlefield V (DICE, 2018) the concept of "aesthetic memory" is defined and illustrated. Said concept is understood as the reproduction of defining, popular images of a historical moment. They are images selected by different social groups, unrelated to the historian's job, whose function is to consolidate the historical credibility of the product and which are considered as canonical and representative of a particular moment.
\end{abstract}

Keywords: History. Public uses of History. Memory. Aesthetics. Video games. Art of mass consume.

\title{
Introducción
}

El día 23 de mayo de 2018 Electronic Arts publicó el primer vídeo para presentar el videojuego Battlefield $V^{2}$. En este cortometraje aparecía una mujer portando un rifle de asalto con una mano prostética. La protagonista, junto a un equipo mayor, participaba en el conflicto armado con la misma intensidad que la del resto de sus compañeros.

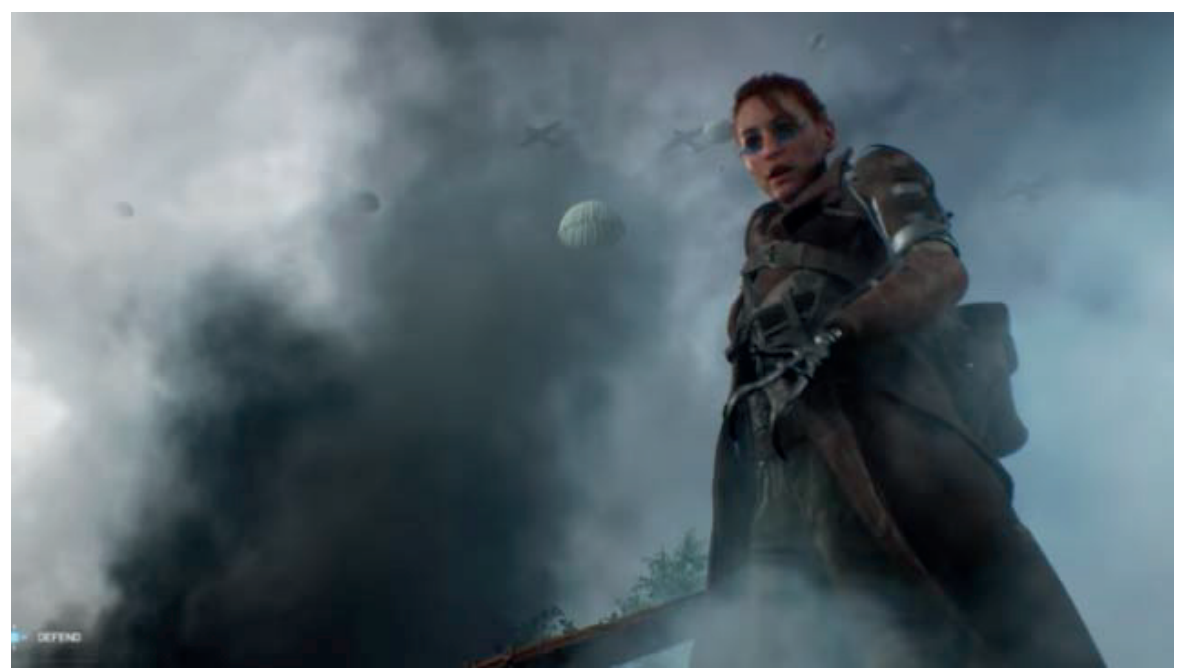

Ilustración 1: Captura de pantalla de Battlefield $V$ donde podemos apreciar la mano metálica y los tatuajes en el rostro de la mujer protagonista.

2 Consultado el 28 de octubre de 2018 desde https://www.youtube.com/watch?v=a7ZpQadiyqs. 
Durante esa misma semana aparecieron dos respuestas al vídeo, aquella que defendía la presencia femenina en el videojuego y aquella que criticaba su presencia. Los segundos crearon en la red social Twitter una etiqueta bajo el nombre \#NotMyBattlefield ${ }^{3}$, trataron de organizar campañas para evitar la salida del títu$10^{4}$ y calificaron al vídeo de presentación en la plataforma YouTube con más de 530.000 votaciones negativas, frente a las 347.000 positivas ${ }^{5}$. Todas las críticas se encontraban arropadas bajo la defensa del rigor histórico.

Si observamos más de cerca estas críticas podemos observar que guardan un punto en común: el rechazo a la presencia femenina. Estos ataques guardan relación con otros movimientos dentro de la cultura del videojuego relacionados con el fenómeno del "gamergate" (Mortensen, 2016, Massanari, 2016, Shaw, 2015). Las críticas recibidas por el vídeo de presentación no apuntaban a otros asuntos problemáticos y enfrentados a la historia como el tipo de acción, la sobreexplotación y sobrerrepresentación de escenarios, la incidencia sobre el héroe-ciudadano, el frente de guerra como galería de tiros para el soldado de infantería, etc (Sottek, 2018). En cambio todos los ataques se centraban en la presencia de la mujer y estaban fundados en una supuesta defensa del rigor histórico.

Los primeros, los que defendían la presencia femenina, pudieron leer en la prensa del videojuego numerosos artículos tratando de defender la representación de mujeres en el frente militar de la Segunda Guerra Mundial (Plunkett, 2018, Martin, 2018, Farokhmanesh, 2018). La mujer, en el frente oriental, si participó en actividades armadas como demuestran los trabajos de recuperación de la memoria oral realizados por Lyuba Vinogradova $(2017,2016)$ y Svetlana Aleksiévich (2015) además de los diarios publicados de la francotiradora Liud-

3 En la red social Twitter una etiqueta (o hashtag) es una palabra que puede rastrearse en los mensajes de todos los usuarios que la han utilizado. El caso de \#NotMyBattlefield aún se encuentra vigente y puede consultarse en la siguiente dirección: https://twitter.com/ search?q=\%23notmybattlefield\&src=typd. En ella podemos leer mensajes que relacionan al videojuego con el feminismo, como este del usuario @T4isonTV publicado el 23 de mayo de 2018 donde afirma que: «\#notmybattlefield Los SJW y el feminismo se están cargando mi saga favorita. Hasta el Call of Duty WW2 me atrae más que esto. Espero que recapaciten y pongan más Stalingrado y menos corrección política. Estamos hablando de lo más cruel que le ha pasado a la humanidad". Otros, en cambio, achacan la falta de rigor histórico, como este comentario de @xdFrancesc publicado el 22 de agosto: "La batalla es en Amsterdam en el 1940 pero las tropas alemanas llevan fusiles de asalto StG-44, ok. Ese soldado alemán con una arma que le faltan 3 años para existir es una mujer o un hombre no blanco, \#NotMyBattlefield".

4 Campaña iniciada en el portal Change.org titulada "Remove Historical Inaccurate Customization from Battlefield 5 or We Boycott" y firmada por más de 2.900 personas. Consultado el 28 de octubre de 2018 desde https://www.change.org/p/dice-boycott-battlefield-5.

5 Consultado el 11 de noviembre de 2019 desde https://www.youtube.com/watch?v=fb1MR85XFOc. 
mila Pavlichenko (2019). Sin embargo no ocurrió lo mismo en el frente occidental europeo. Dentro de este conflicto la mujer tuvo una participación mucho más minoritaria que en el oriental. En este escenario es donde se encuentra ambientado el videojuego en cuestión. En él la mujer tuvo un papel de apoyo y soporte que destacó en apartados de vital importancia para el desarrollo del conflicto como las fotografías aéreas y su interpretación (Halsall, 2012). Algunas de ellas tuvieron una breve instrucción y participación como pilotas (Schrader, 2006) además de participar en actividades de resistencia, espionaje, sabotaje y rescate (Atwood, 2011). Sin embargo no participaron en actividades de infantería ni en conflictos relacionados directamente con el frente. Momento que describe y enseña el videojuego. Por lo tanto ninguno de los grupos contaba con la razón en este asunto.

Porque aunque si participaron mujeres en el frente armado no fue en el escenario donde muestra el videojuego. Las críticas hacia el rigor histórico son comprensibles aunque todas las examinadas para este trabajo han apuntado a la presencia de la mujer en exclusiva, en lugar de observar otras irregularidades igual de flagrantes. La conclusión a todo este debate lo aportó la propia compañía de distribución y el estudio de desarrollo del videojuego, propiedad del primero, Electronic Arts y EA Digital Illusions CE, quien afirmó que la literalidad en la representación del pasado no les importaba (Arif, 2017).

El debate, por lo tanto, no era sobre si participaron, en la Segunda Guerra Mundial, mujeres en el frente europeo occidental, el debate era sobre la inclusión de un elemento poco representado: la mujer como protagonista en un videojuego bélico de contenido histórico. Este hecho nos remite a otro asunto muy diferente: la lucha entre diferentes memorias, una fuerte personificada en aquellos criticaban la representación femenina, y una débil en pugna por la primera con el objetito de sustituirla representada por aquellos que apoyaban la representación femenina. Una lucha que nada tenía que ver ya con la historia sino con su representación mediática en los medios de comunicación de masas.

Battlefield $V$ rompió una tradición icónica y visual que se remonta en el videojuego hasta su origen: el protagonismo del hombre en los videojuegos bélicos de contenido histórico, con escasas excepciones como Medal of Honor: Underground (Dreamworks Interactive, 2000). El resto de las transgresiones históricas que cometía el título poco importaba a la comunidad de jugadores. El hecho que desató la polémica fue la inclusión de una mujer como protagonista, rompiendo la tradición estética de la saga y el medio. Un hecho que se ha repetido en otras ocasiones como en la inclusión de generalas en el videojuego Total War: Rome II (The Creative Assembly, 2013), decisión que desató de nuevo la polémica entre un grupo de aficionados con la intención de eliminar esta faceta del juego por ser "poco histórica" (Alexander, 2018) o en Assassin's Creed: Odyssey (Ubisoft, 2018). En este título ocurrió exactamente la misma situación, la empresa res- 
ponsable decidió situar a una mujer como protagonista y grupos de aficionados rechazaron esta decisión por no ajustarse a la realidad histórica conocida, mientras pasaban por alto otros errores históricos de bulto (Brown, 2018).

Las tres polémicas presentadas demuestran que existe una memoria estética que al ser cuestionada provoca determinadas respuestas de diferentes grupos sociales, como la crítica destructiva por parte de un grupo de aficionados que siente perder algo considerado como suyo o el aplauso por parte de otros grupos que se consideran más identificados con la nueva representación. Una lucha entre dos tipos de memoria, la hegemónica y la débil, que aspira a remplazar a la primera a través del empleo de imágenes.

\section{Metodología}

Los tres ejemplos anteriores ponen de manifiesto la existencia de una memoria estética cuya ruptura ha provocado una fuerte oposición por parte de un grupo de aficionados. Una memoria estética entendida como una repetición de imágenes y motivos cuya presencia favorece la verosimilitud histórica del videojuego histórico y su asimilación con otros productos similares ambientados en el mismo momento. Una forma de representar y recordar el pasado que ha roto con la historia en tanto cuanto disciplina que se ocupa del estudio del ayer.

Esta reproducción de imágenes pretendidamente históricas y seleccionadas por diferentes grupos sociales con motivos heterogéneos favorece la creación de dicha memoria estética y ayuda a crear escenas pretendidamente históricas o "retrolugares" (Venegas Ramos, 2018). Tal y como hemos podido comprobar en la presentación, todas las críticas realizadas a los cambios introducidos en los tres títulos compartían el mismo argumento: falta de verosimilitud histórica

El objetivo de este trabajo es dejar de manifiesto esta situación a través de la observación de títulos muy populares que han mantenido dos posturas diferentes con respecto a la memoria estética, el continuismo: Call of Duty: WWII (Sledgehammer Games, 2017) y el rupturismo parcial: Battlefield V (DICE, 2018) junto a otros títulos que nos sirvan para ofrecer el contexto necesario a nuestro trabajo. A través del análisis de las imágenes y las polémicas generadas, o no, por estas obras podremos concluir la existencia, o no, de una memoria estética en el videojuego histórico y de contenido histórico ${ }^{6}$. Un trabajo que puede insertarse en un contexto mucho más amplio sobre el estudio de la me-

6 El videojuego que representa el pasado puede dividirse en videojuego histórico, si está basado en fuentes primarias y obras historiográficas y su intención es "poner en imágenes interactivas la historia", y videojuego de contenido histórico si está basado en la memoria estética de la cultura de masas y su intención es ofrecer una satisfacción inmediata al jugador. Ambos comparten cuatro características básicas: veracidad, verosimilitud, información y libertad aunque distribuidas de manera desigual (Jiménez Alcázar, 2018: 158-160) 
moria en los productos de los medios de comunicación de masas ambientados en el pasado cuyos resultados pueden iluminar nuevos rincones de nuestra relación con el ayer.

Tal y como hemos apuntado, para tratar de demostrar la existencia de una memoria estética en el videojuego histórico, observaremos una cuestión fundamental en cada uno de los títulos: la existencia o inexistencia de polémicas que tengan como base la representación visual o textual del pasado. Esta observación nos permitirá determinar el grado de aceptación, continuidad o ruptura de determinadas imágenes o motivos visuales.

El segundo método que emplearemos para determinar la existencia, o no, de dicha memoria es la referencialidad, es decir, el reciclaje de imágenes, motivos o temas entre distintos productos culturales ambientados en el pasado. De esta forma deseamos mostrar como los videojuegos históricos y de contenido histórico han empleado, y siguen empleando, mensajes e imágenes ya existentes en obras anteriores ambientadas en momentos históricos similares con la intención de equiparar su contenido al existente para potenciar la "sensación de historia" y mantener una memoria oficial visual.

Ambos métodos se encuentran integrados en el contexto historiográfico necesario para dotar de fondo y significado nuestros argumentos sobre el tema. Para ello emplearemos de manera especial los trabajos sobre cultura y medios de comunicación de masas del sociólogo francés Gilles Lipovetsky y los trabajos sobre memoria de Enzo Traverso y Debra Ramsay.

Lamentablemente el videojuego histórico y de contenido histórico no ha sido aún considerado como memoria en trabajos anteriores salvo casos puntuales como la obra de Debra Ramsay American media and the memory of World War II en la que la autora defendía la existencia de mediaciones maestras (Ramsay, 2015, 83) para la representación mediática del pasado. Este concepto lo emplearemos en nuestro trabajo de manera especial ya que títulos como Medal of Honor han logrado convertirse en mediaciones maestras, es decir referencias ineludibles en la representación de un momento pasado dentro de los medios de comunicación de masas dada su conversión en pieza fundamental del recuerdo. Una referencia cuya ruptura, como en el caso de Battlefield $V$, provoca extrañeza ante lo mostrado y críticas ante la falta de literalidad.

Y es que consideramos que el videojuego histórico y de contenido histórico es una forma de memoria y no una forma historiográfica, tal y como apuntan otros estudiosos sobre el tema. Una forma de memoria explicitada en la obra de Enzo Traverso, El pasado, instrucciones de uso, en la cual definía el concepto dentro de nuestra contemporaneidad de la siguiente manera:

El pasado se transforma en memoria colectiva luego de haber sido seleccionado y reinterpretado según las sensibilidades culturales, los dilemas éticos y las conveniencias del presente (...). Ese fenómeno revela indudablemente un proce- 
so de reificación del pasado, es decir, su transformación en objeto de consumo, estetizado, neutralizado y rentabilizado listo para que la industria del turismo y del espectáculo lo recupere y utilice (Traverso, 2011, 14).

$\mathrm{Y}$ es que, tal y como hemos podido comprobar en la introducción, el pasado que muestra Battlefield $V$ poco tiene que ver ya con la historia, se ha neutralizado, rentabilizado y preparado para su uso en la industria del espectáculo. Una industria que lo ha proyectado en la pantalla y ha generado su propia memoria, una memoria estética, que lo ha separado por completo de la historia. Entendiendo en este caso la estética de acuerdo a la obra de Lipovetsky La estetización de la realidad: vivir en la época del capitalismo artístico

En la era del capitalismo artístico, hiperespectáculo, consumo y diversión forman un sistema. La diversión no es ya un dominio marginal y separado, sino que se ha convertido en un sector económico mayor, una industria transestética que crece cada día, colonizando cada vez más imágenes, productos y actividades. El universo de la diversión va hoy mucho más allá del cine, la televisión y la música: abarca los objetos, los juegos, la información, la comunicación, las ciudades, los espacios comerciales, los museos, el patrimonio e incluso las celebraciones nacionales. La diversión no se opone ya ni a la economía ni a la vida cotidiana: en el reinado del capitalismo creativo se infiltra en todos los espacios de la vida y se fusiona con el mercado. Estamos en la hora de la diversión integral y generalizada, caracterizada por la hibridación de mercancía, emoción y distracción en masa (2015: 226).

Partiendo, por tanto, de estos tres principios: la existencia de mediaciones maestras, la estetización del pasado y su conversión en producto de consumo, podemos enmarcar el resto de nuestro trabajo.

\section{Continuismo y ruptura de la memoria estética}

\section{El continuismo en la memoria estética oficial de Call of Duty: WWII}

En las últimas páginas de su obra Soldados caídos: La transformación de la memoria de las guerras mundiales George L. Mosse advertía del regreso del mito de la experiencia de guerra bajo la condición del regreso del nacionalismo, este mito...

...está atado al culto de la nación: si este se encuentra en suspensión, como estuvo tras la Segunda Guerra Mundial en la Europa occidental y central, el mito se debilita fatalmente, pero si la religión cívica del nacionalismo vuelve de nuevo a ascender, el mito lo acompañará una vez más (2016: 279)

No son pocos los historiadores que han observado, a partir del año 2001, un nuevo ascenso de la religión cívica del nacionalismo (Rachman, 2018, Clover, 2016, Sutherland, 2011 o Tamir, 2019). Este ascenso ha traído consigo la recuperación del mito de la experiencia de guerra, diseñado... 
...para enmascarar la guerra y hacerla legítima: para desplazar su cruda realidad. La memoria de la guerra se remodeló para convertirla en una experiencia sagrada que había proporcionado a la nación nuevos y profundos sentimientos religiosos (Mosse, 2016: 35).

Fue en Estados Unidos, como respuesta a los atentados del 11 de septiembre, donde este mito de la experiencia de guerra cobró más fuerza (Faludi, 2009 y Dower, 2012). Su expresión más visible fue la representación bélica llevada a cabo en los medios de comunicación de masas (Jung, 2010, Westwell, 2014 y Thomas Payne, 2016) y una de sus principales manifestaciones fue la recuperación de la memoria oficial de la Segunda Guerra Mundial a través de grandes obras de ficción ambientadas en dicho momento (Paget y Lipkin, 2009, Ramsay, 2016 y Venegas Ramos, 2018) en las que se combinó el recuerdo del conflicto con las operaciones militares llevadas a cabo en Oriente Próximo (Dower, 2012, 147-153). Y fue el videojuego, junto con el cine, el medio más representativo de dicha recuperación memorística que ayudó al proceso de trivialización del conflicto, en el cual...

... lo bélico quedaba entretejido en la vida diaria de una manera difícil de reconciliar con la sacralización de la guerra como algo extraordinario. Pero aun así, la trivialización, del mismo modo que la glorificación, ayudó a las personas a hacer frente a la hecatombe (Mosse, 2016: 187).

Mosse examina este proceso de trivialización en el caso de la Primera y la Segunda Guerra Mundial. Sin embargo su análisis es fácilmente extrapolable a la situación actual y el medio del videojuego de guerra. De acuerdo a Mosse fueron los juguetes, juegos y objetos militares empleados en momentos cotidianos los que contribuyeron a dicha trivialización del conflicto y su posterior mitificación (2016: 202), junto a, especialmente, las postales bélicas enviadas desde el frente y desde las instituciones. Los primeros, "los soldados de plomo", de acuerdo al historiador:

...eran los juguetes de guerra más populares, y aunque eran primariamente para niños, a muchos adultos también les gustaban. Su atractivo dependía en gran medida del realismo con que representaban a los soldados y sus armas, de manera que fuese posible recrear guerras y batallas lo más realistamente posible (2016: 182-183).

El videojuego comparte con los soldados de plomo esa pretensión de realismo. El baremo para criticar positiva o negativamente un videojuego de guerra es, precisamente, su capacidad de "recrear guerras y batallas lo más realistamente posible", un objetivo que también es empleado como elemento de márquetin. Los responsables de Call of Duty: WWII recorrieron los lugares que aparecen en su videojuego para recrearlos a través de fotogrametría, visitaron campos de 
batalla, fotografiaron decenas de armas y contaron con la asesoría de un historiador, Martin Morgan ${ }^{7}$, y la ayuda de veteranos de guerra (Parker, 2017). Grabaron sonidos reales de vehículos y objetos de la época para representarlos de la manera más auténtica posible (Andersen, 2018). Es evidente, por tanto, la pretensión del estudio de recrear "guerras y batallas lo más realistamente posible". Sin embargo no todo aparecía en la pantalla.

Tal y como hemos mencionado Mosse citaba a las postales de guerra como otro de los principales agentes de trivialización de la guerra en las sociedades europeas durante la Primera Guerra Mundial, unas postales que presentaban unas características muy similares al videojuego de guerra contemporáneo:

El mito de la experiencia de guerra apareció primero en postales que desinfectaban lo bélico, mostrando su maleabilidad. (...) No hay dibujos de los muertos o heridos como tenían que haber aparecido en las trincheras. Raramente se retrata la muerte, y cuando aparece es tranquila y serena. La muerte heroica en batalla sí se representa, si no en las postales, en periódicos ilustrados (...) Similarmente, aunque los heridos aparecen más frecuentemente en las postales, sus heridas son normalmente leves y están bien vendados, sin mucha sangre a la vista; además, estos heridos normalmente están atendidos por preocupados camaradas o por compasivas enfermeras (2016: 172).

Títulos como Call of Duty: WWII reproducen todas estas características en las imágenes, diseños y mensajes que presentan al usuario. Sus responsables han eliminado la sangre y los muertos. El proceso de deshumanización llevado a cabo en este título y otros de la misma categoría ha generado la conversión del enemigo en diana (Venegas Ramos, 2018, 2019), característica fundamental del mito de experiencia de guerra (Mosse, 2016: 219). Sin embargo la muerte de sus protagonistas si se refleja como un sacrificio heroico en mor de un bien mayor. Así lo demuestran escenas del título de Sledgehammer como la protagonizada por Daniel quien, cargando con su moribundo compañero Turner, se enfrenta a decenas de enemigos mientras trata de salvarlo y ponerlo al resguardo de las balas alemanas. Para que, una vez parapetado, Turner recoja un fúsil y mantenga a los soldados de la Wehrmacht ocupados mientras sus compañeros logran escapar del peligro.

7 Historiador que también participó en la serie Hermanos de Sangre (2001) y Salvar al Soldado Ryan (1998) junto a Stephen E. Ambrose, historiador en el que se basan las nuevas producciones cinematográficas y videolúdicas estadounidenses de la Segunda Guerra Mundial del siglo XXI. 


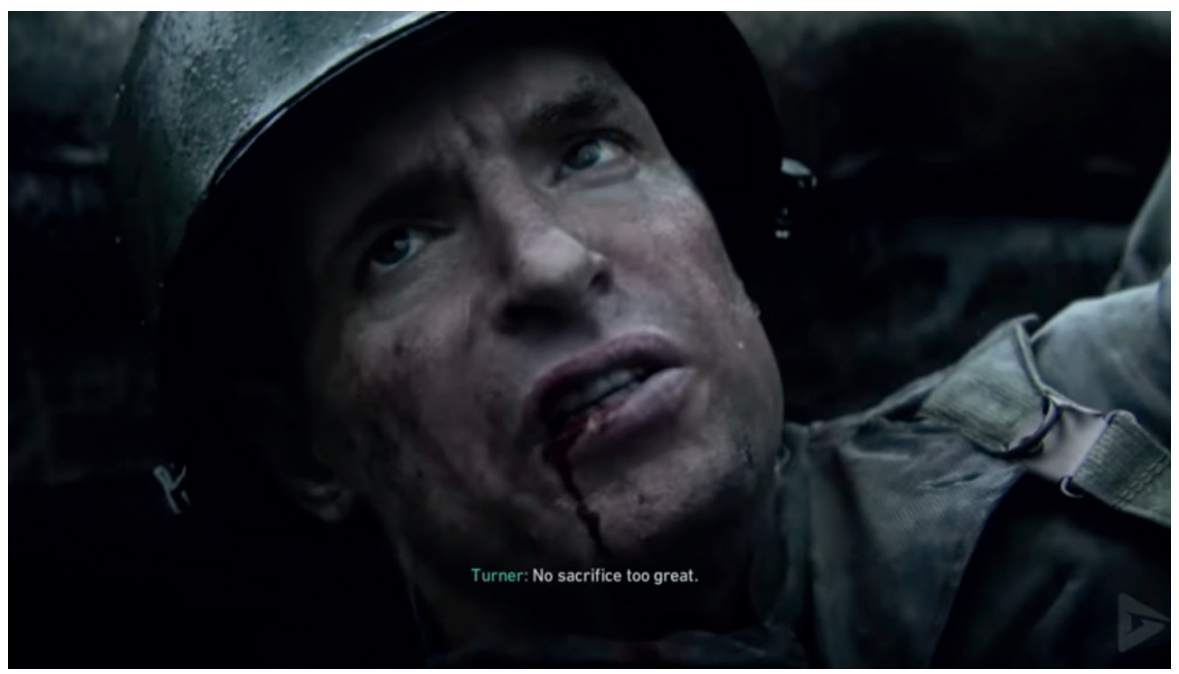

Ilustración 2: Captura de pantalla de Call of Duty: WWII en la que podemos leer las palabras del soldado Turner antes de morir: "ningún sacrificio es demasiado grande".

Tanto las características de los juguetes y la de las postales de la Primera Guerra Mundial como sus objetivos relacionados con la trivialización de la guerra y la divulgación del mito de la experiencia de guerra podemos encontrarlo en los videojuegos militares ambientados en la primera y segunda contienda mundial, los cuales han generado una fuerte memoria estética del conflicto que ha servido para trivializar, y glorificar, la práctica bélica (Huntemann y Payne, 2009; Salvati y Bullinger, 2013).

El mito de la experiencia de guerra y la trivialización de la guerra que lo apuntala se encuentra con facilidad en el videojuego de guerra ambientado en la Segunda Guerra Mundial. En él encontramos todas las características presentadas por Mosse ${ }^{8}$. Los estudios responsables, habitualmente estadounidenses aunque no exclusivamente, se basan en dos fuentes principales, la memoria oficial del conflicto tal y como demuestra la colaboración con instituciones militares, de veteranos y gubernamentales así como la cesión de licencias militares y comerciales para representar sus contenidos (Mead, 2013, Stahl, 2009 y Lenoir y Caldwell, 2018), y la memoria estética de la guerra, cuya fuente es aquello que Fussell denominaba "cultura moral" de la guerra (2003: 205), reproducida en

8 Aunque nosotros vamos a hacer especial hincapié en la trivialización y estetización del conflicto existen muchos otros elementos en el videojuego que sustentan el mito de la experiencia de guerra como la pretensión de honrar a los caídos y glorificar la práctica bélica. Temas que podrán ser desarrollados en futuros trabajos. 
los medios de comunicación de masas a través de clichés (2003: 238), lugares comunes que en el videojuego comienzan en 1999 con la publicación, por Dreamworks Interactive, de Medal of Honor ${ }^{9}$.

Este videojuego fue producido por Steven Spielberg, como producto de acompañamiento a su desembarco en televisión y cine. Salvar al Soldado Ryan, Hermanos de Sangre y Medal of Honor forman una trilogía transmedia de productos audiovisuales que rescataron el mito de la experiencia de guerra y consolidaron una nueva forma de percibir el conflicto como una "mediación maestra":

.... a representation in any medium that claims the status of a defi nitive account of the war and of the wartime generation's experiences and memories and that subsequently functions as a touchstone for ensuing representations of the conflict throughout the transmedia structure (Ramsay, 2016, 83)

Una mediación maestra que acudía a los clichés cinematográficos de la Segunda Guerra Mundial (Suid, 2002: 627) cuya fuente era la cultura de la moral advertida por Fussell en su obra Tiempos de guerra: conciencia y engaño en la Segunda Guerra Mundial (2003) y que hacía "amplio uso de materiales visuales para desinfectar, dramatizar y romantizar la guerra, no solo mediante imágenes, sino también sistematizando símbolos (...) Así, el mito [de la experiencia de guerra] llevó con éxito su mensaje a la gente" (Mosse, 2016: 94).

Medal of Honor tuvo, en el videojuego, el mismo papel que Salvar al Soldado Ryan en el cine o Hermanos de Sangre en la televisión, sirvió de mediación maestra y vehículo del mito para el resto de producciones posteriores. Las características formales de este videojuego: perspectiva en primera persona, deshumanización de los enemigos, espacio como galería de tiros, eliminación de la sociedad civil, interacción del personaje protagonista masculino con el resto de elementos a través del disparo y pretensión de realidad a través de la representación fotorrea-

9 La Medalla de Honor es la condecoración militar más prestigiosa de los Estados Unidos. Los dirigentes de The Congressional Medal of Honor Society, un grupo de veteranos de guerra responsables de otorgarla de acuerdo a criterios relacionados con la "valentía e intrepidez con riesgo de la propia vida, más allá de la llamada del deber, estando en combate contra un enemigo de los Estados Unidos", interpuso una queja a DreamWorks Interactive para que cambiaran el nombre de su videojuego (Redacción de Edge, 2011) ya que una obra digital que contuviera el nombre de la medalla podía empañar su prestigio. La solución a este conflicto la encontró Peter Hirschmann al invitar a los responsables del galardón al estudio para que vieran el videojuego. Paul Bucha, presidente de la Congressional Medal of Honor Society, recorrió el estudio y entrevistó a los trabajadores. Cuando volvió de nuevo con sus compañeros, no solo retiró la queja sino que apoyó y promocionó el videojuego debido a los valores que éste defendía. Esta anécdota muestra como los valores e ideas que aparecen en Medal of Honor se encuentran en consonancia con aquellas más respetadas y defendidas por grupos tan conservadores en cuanto a su sentido del pasado de Estados Unidos como las instituciones militares.

Pasado y Memoria. Revista de Historia Contemporánea, 20, 2020, pp. 277-301 
lista, se mantuvieron inalteradas durante años conformando una fuerte memoria estética del conflicto en el videojuego de guerra.

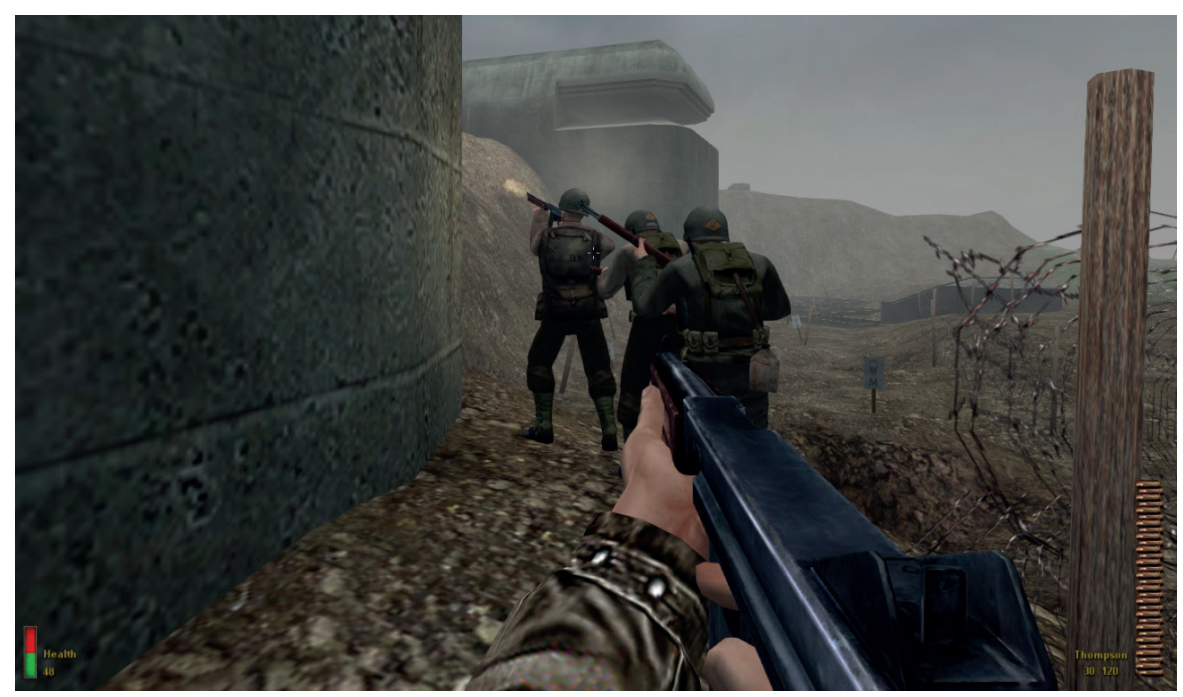

Ilustración 3: Captura de pantalla de Medal of Honor, 1999.

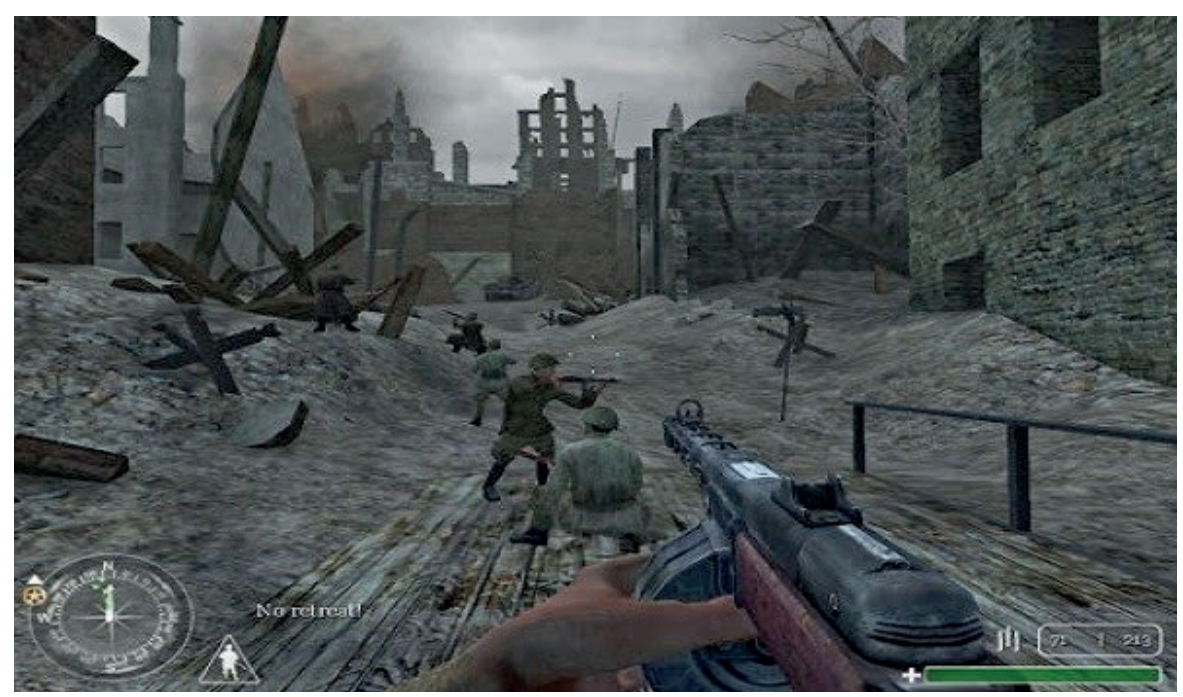

Ilustración 4: Captura de pantalla de Call of Duty ${ }^{10}, 2003$.

10 La saga Call of Duty fue creada por la empresa de desarrollo de videojuegos Treyarch, antiguos trabajadores de Dreamworks Interactive, responsables de Medal of Honor. 


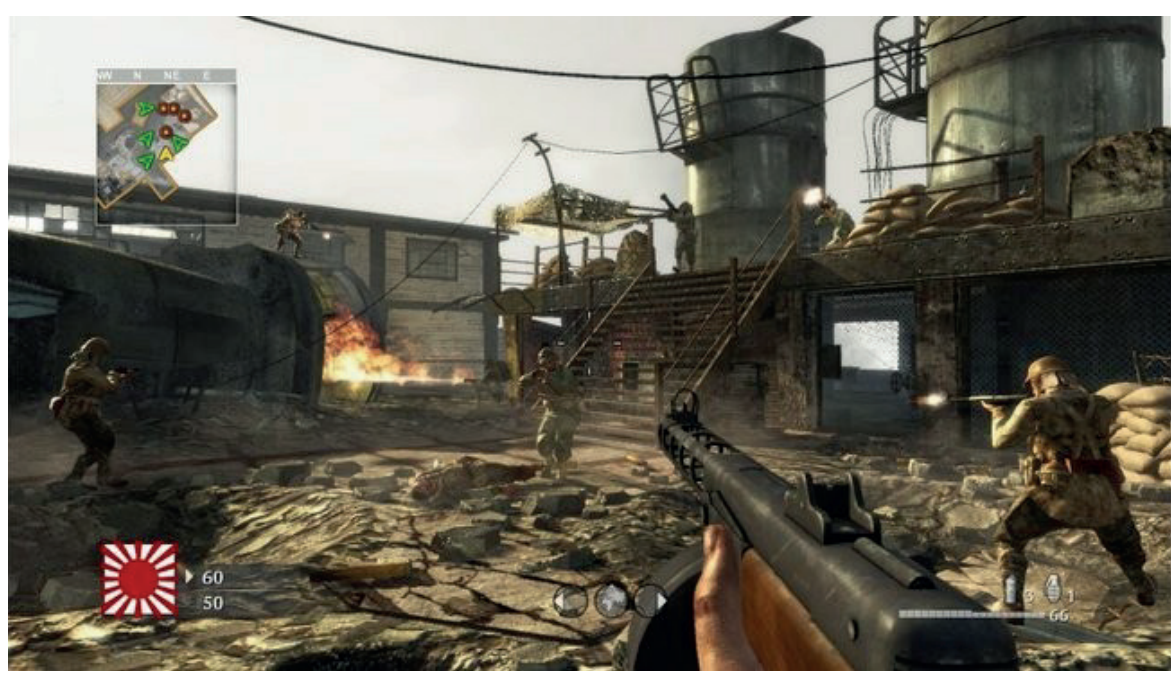

Ilustración 5: Captura de pantalla de Call of Duty: World at War, 2007.

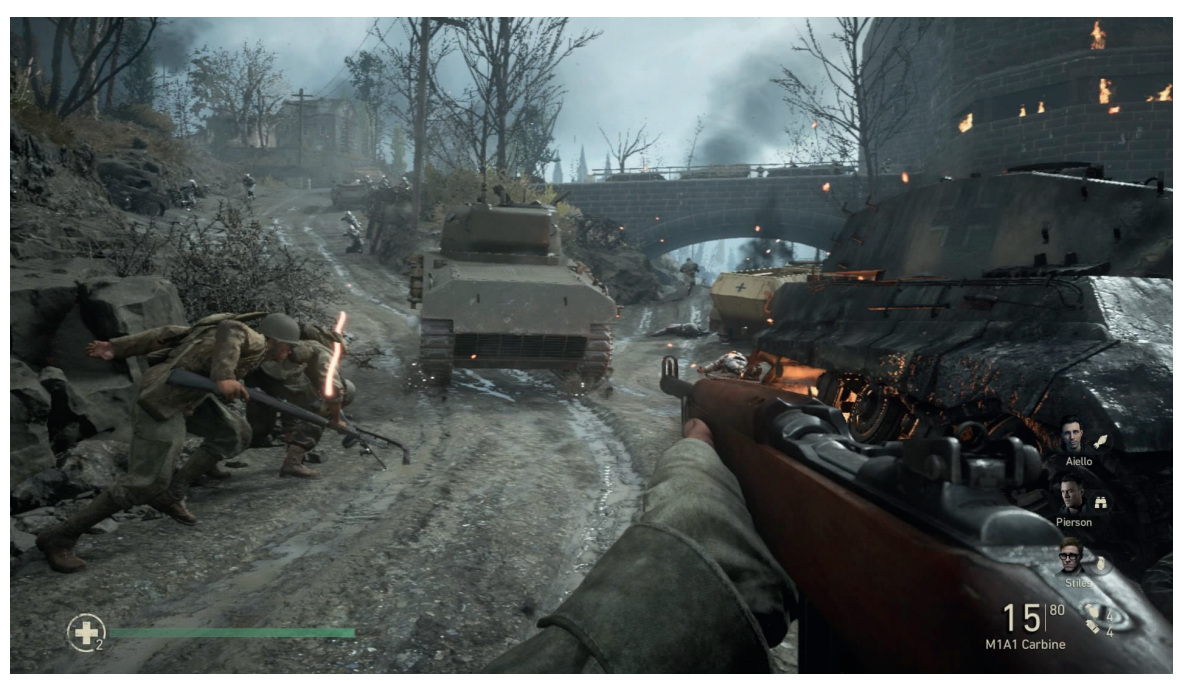

Ilustración 6: Captura de pantalla de Call of Duty: WWII, 2017.

Como podemos observar en las ilustraciones anteriores, existe una clara continuidad estética en los videojuegos de acción ambientados en la guerra. Todos ellos comparten las características citadas con anterioridad envueltas en la memoria oficial de la Segunda Guerra Mundial, confinadas en la idea de "época carismática" definida por Ramsay como "a set of circumstances and experiences 
that resonates across media and through time in a process of continual evaluation of past, present, and future" (2016: 36) cuyas claves fundamentales han sido el soldado-ciudadano, la "guerra buena" y la construcción visual de la guerra, ya tratada con anterioridad. Todo ello ha generado una memoria estética que bebe de las imágenes y mensajes ofrecidos por la memoria oficial estadounidense del conflicto que, a opinión de Fussell, nunca pudo comprender el conflicto:

La guerra real fue trágica e irónica, superando la capacidad reveladora de cualquier análisis literario o filosófico, pero, especialmente en una Norteamérica no bombardeada, el significado de la guerra pareció inaccesible. (...) Norteamérica no ha entendido todavía como fue la Segunda Guerra Mundial, y por lo tanto no ha podido usar esa comprensión para reinterpretar y redefinir la realidad nacional y para alcanzar algo parecido a la madurez pública (2003: 334).

A cambio de esta comprensión Estados Unidos ha generado, a partir de la guerra, una época carismática representada en mediaciones maestras de las que surge el mito de experiencia de guerra representado a través de clichés y que ha tenido a uno de sus mejores representantes en el videojuego. Lejos deben quedar las consideraciones de las representaciones bélicas en el videojuego histórico o de contenido histórico como una selección de elementos que aportan "autenticidad" tal y como apuntaban Bullinger y Salvati en su trabajo "Selective Authenticity and the Playable Past". Tal y como hemos podido demostrar la memoria estética de la guerra se alarga más allá de los medios de comunicación de masas y conserva una función evidente: conservar intacto, tanto en estética como en contenido, una época memorable que sirva para consolidar la memoria oficial del evento. Cómo hemos tenido ocasión de examinar, y examinaremos con más detalle en páginas posteriores en relación a la memoria estética del Holocausto, cualquier cambio en esta memoria estética del conflicto genera conflicto y/o polémicas entre autor o autores, público e instituciones oficiales.

\section{La ruptura parcial en la memoria estética oficial de Battlefield V y otros títulos ambientados en la Segunda Guerra Mundial}

La repetición de los mismos diseños, imágenes y mensajes en el videojuego de acción ambientado en la Segunda Guerra Mundial ha creado una memoria estética reproducida en cientos de otros títulos que trataban de aprovechar aquello que Adam Chapman denominó "resonancia histórica":

Historical resonance is the recognition of the game as in some way sufficiently real (referential) in its relation to the past as it is understood by the player, and therefore relating to their local context and constituting a shared history (with the global, as represented by the game) (2016: 36).

Chapman, en su trabajo Digital Games as History: How Videogames Represent the Past and Offer Access to Historical Practice defendía que esta resonancia histó- 
rica y el propio videojuego histórico y de contenido histórico podía ser historia. El autor sigue una línea de pensamiento muy influida por investigaciones en campos paralelos como el del cine llevado a cabo por Rosenstone donde éste defendía los mismos puntos para el estudio del cine. Ambos acercamientos, al videojuego de Chapman y al cine de Rosenstone (2006), son discípulos de las obras de Hayden White y su crítica posmoderna de la historiografía, desarrollada en sus libros Metahistory: The Historical Imagination in Nineteenth-Century Europe y The Content of the Form: Narrative Discourse and Historical Representation. Nosotros consideramos que si bien el videojuego histórico, no el del contenido histórico, podría llegar a ser historia aún no lo es en la actualidad y como consecuencia del formato videolúdico y los factores de producción y distribución actuales es imposible que llegue a serlo (Venegas Ramos, 2018). Esta misma critica a White la han realizado otros académicos como Ginzburg (2010: 297326) o Traverso, quien argumentaba que éste, y esta es una crítica extensible a Chapman, identificaba "la narración histórica con la invención literaria, que se funda ambas, según él, en las mismas modalidades de representación" (2011: 64). Nosotros defendemos que los medios de comunicación de masas y las obras de arte para el consumo de las masas produce una memoria estética separada por completo de la historia. Un fenómeno que crea dos planos, dos formas de acercarse al ayer, de nuevo, de acuerdo a Traverso:

... la memoria se presenta como una historia menos árida y más «humana». La memoria invade hoy el espacio público de las sociedades occidentales: el pasado acompaña al presente y se instala en su imaginario como una «memoria» poderosamente amplificada por parte de los medios de comunicación, a menudo dirigida por los poderes públicos (2011: 13).

El videojuego que representa el pasado es considerado "histórico" no por su parecido con la historia sino por su similitud con otros productos de éxito publicados con anterioridad y ambientados en un contexto similar. Cualquier título que rompa la similitud con la memoria estética generada, aunque se acerque más al pasado, será tildado de inexacto o polémico. Uno de los ejemplos que prueba este hecho es el ejemplo que abre este artículo, el videojuego Battlefield $V$. La decisión del estudio de incluir a una mujer como protagonista del videojuego despertó la polémica entre los aficionados, acusando al título de "inexacto" con la realidad histórica (Farokhmanesh, 2018). Las críticas realizadas por estos usuarios apuntaban a la presencia de la mujer como la principal causa de inexactitud histórica de la saga, sin embargo nada mencionaban de todas las demás inexactitudes que presentaba la obra. Este hecho demuestra la existencia de una memoria estética cuya ruptura provoca acusaciones de inexactitud histórica, aun cuando la obra presente otros flagrantes errores históricos. No es el único caso que prueba nuestra hipótesis. La misma empresa, DICE, fue objeto 
de críticas de inexactitud histórica, por parte de un gran número de usuarios, como consecuencia de la incorporación de un personaje afroamericano como protagonista del videojuego Battlefield 1 (DICE, 2017) ambientado en la Primera Guerra Mundial (Pearson, 2016).

Otra faceta de la memoria estética de la Segunda Guerra Mundial guarda relación con el Holocausto y su inexistencia. En el videojuego no aparece y las ocasiones en las que lo ha hecho han provocado fuertes polémicas, como es el caso de Wolfenstein: The New Order (Machinegames, 2014). No podemos de perder de vista que esta primera incursión del jugador en un campo de concentración se realiza en un videojuego de ciencia ficción ambientado en unos ucrónicos años sesenta dentro de una obra claramente exagerada, satírica y cercana a la psicodelia más violenta y brutal.

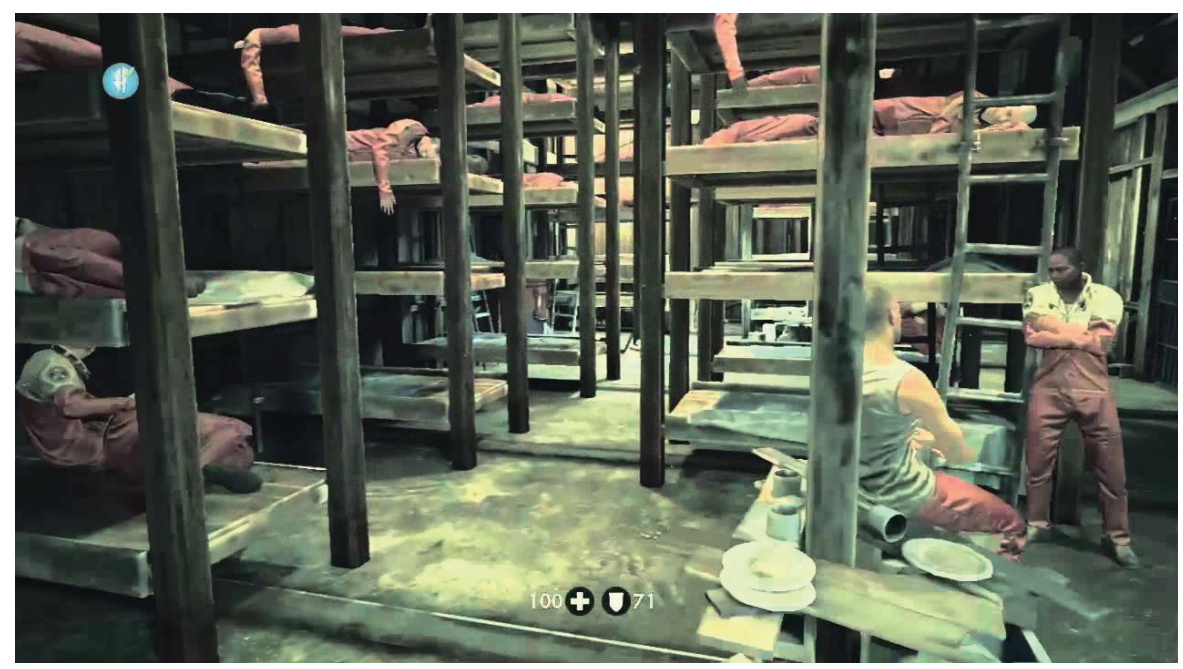

Ilustración 7: Captura de pantalla de Wolfenstein: The New Order donde podemos observar la representación más popular de los campos de concentración sin muestra alguna de lo ocurrido en su interior.

Tomar la decisión de incluir campos de concentración se debió al escenario y la temática fantástica. Un elemento que en un contexto más real con pretensión de "literalidad" podía resultar ofensivo o, al menos, polémico (Bauman, 2013). Pete Hines, uno de los responsables de la obra, durante una entrevista ofrecida al periódico The Times of Israel trataba de contextualizar la inclusión de los campos en el videojuego:

You're talking about a game with robot dogs and giant mechs that roam the cities, where it is the 1960s where the Nazis have taken over the world, they 
got to the moon first and all of these other things. It's pretty clear what you are doing in the game doesn't have much basis in reality. Although, to your point, it does touch on a subject that does have some connective tissue to things that happened in the past (Hoffman, 2014).

Este tono voluntariamente exagerado permitió su lanzamiento en Alemania, la primera vez que un título de esta saga era publicado en el país. Antes de su publicación hubo un periodo de adaptación del título a las leyes alemanas de representación del nazismo en el que se eliminó cualquier símbolo o referencia al Tercer Reich.

Esta decisión de incluir, u ocultar, elementos polémicos para las sensibilidades contemporáneas en videojuegos de ciencia ficción referentes al pasado puede llegar a ser un arma de doble filo. Por un lado los estudios logran incluir discursos, hechos e ideas que en otros videojuegos con pretensión de autenticidad o literalidad histórica sería imposible como consecuencia de la potencial polémica que podrían llegar a generar pero, por otro lado, pueden llegar a blanquear el recuerdo del pasado y convertir hechos tan dramáticos como el Holocausto o el genocidio de eslavos, romaníes, discapacitados físicos o mentales en invisibles y, por lo tanto, no ocurridos. En el libro The Dark Side of Play. Controversial Issues in Playful Environments (2015) y su capítulo "Exploring the Limits of Play: A Case Study of Representation of Nazism in Games", escrito por Adam Chapman y Jonas Linderoth, los autores reflexionaban sobre las razones y las causas por las que el soldado alemán ha sido desterrado de la Segunda Guerra Mundial digital y la ocultación de los hechos más traumáticos del conflicto. Una de las razones esenciales que esgrimían es que los videojuegos habían sido identificados como un producto capaz de provocar emociones más fuertes de identificación que el cine o la literatura y, por lo tanto, al controlar a un soldado alemán, el jugador puede verse abocado a identificarse con él. Otra de las razones que esgrimían los autores es la facilidad que aportaba situar al soldado nazi como enemigo. Sin embargo no son pocos los estudios que confirman que el videojuego no impacta en el consumidor más o menos que el cine o la literatura (Zendle, Kudenko y Cairns, 2018; Kühn, Kugler, Schmalen, Weichenberger, Witt y Gallinat, 2018; y Anderson, Gentile, Buckley, 2007)

El ocultamiento o estetización de los hechos e ideas más brutales y violentas del conflicto es un rasgo común en las representaciones de la guerra tanto en la actualidad como en el pasado y así lo apuntábamos en las primeras páginas de este trabajo a través de la obra Mosse y su estudio de la formación del mito de la experiencia de guerra. Éste hecho se debe principalmente a las razones ya citadas: continuar y reproducir los mismos referentes con la intención de provocar una sensación de "histórico" en el jugador a través de la reafirmación de la memoria estética e introducir cambios ligeros dentro de una estructura homogénea para ofrecer la sensación de novedad al usuario. La siguiente aparición del Ho- 
locausto en un videojuego, Call of Duty: WWII, siguió el mismo cauce y repitió lo ya visto en Wolfenstein: The New Order con ligeras modificaciones. La razón de esta incorporación temática al juego fue, de acuerdo a uno de sus responsables, las peticiones hechas por la comunidad de jugadores:

I just feel like the audience expectations and the maturity have changed, (...) I know when I play a great single player game and I want a great story, it's no longer enough just to have it be very surface-level and simple. I want something deeper and more complex, just like I do out of the movies I watch. So it's just maturity, I think. People are ready for it. They want it (Rosenberg, 2017).

Y la fuente para representarlas la serie de televisión Hermanos de Sangre (Kuchera, 2017). De acuerdo a sus responsables, en la anterior entrevista citada, las imágenes y la inspiración para recordar el Holocausto partió de la creación de Steven Spielberg aplicando un baño antiséptico y esterilizante a las imágenes para que estas no fueran polémicas, tal y como confirma Michael Condrey en dicha entrevista:

The game clearly has no problem showing the all-out slaughter of hundreds of soldiers, some in incredibly gruesome ways, but when it comes to the intimate and targeted horror of concentration camps, Call of Duty: WWII opts for a more antiseptic presentation. The game aspires to be like the great WWII films, but is unwilling to go to the lengths those films to do present the truth, as grim and monstrous as it is (Kuchera, 2017).

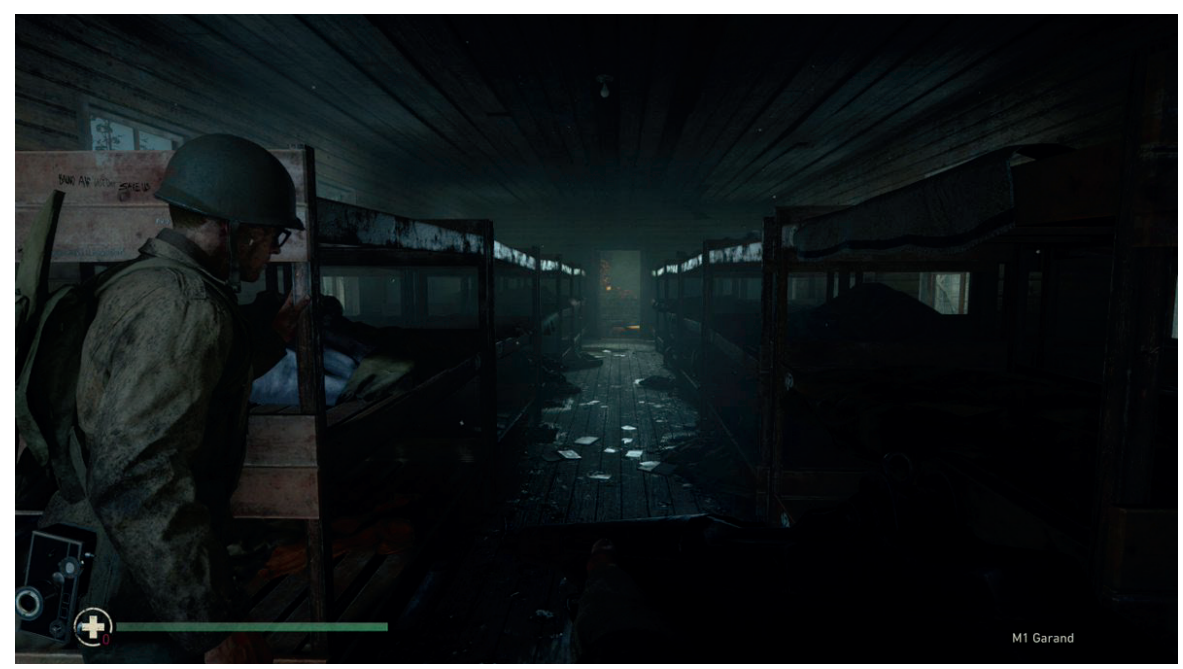

Ilustración 8: Captura de pantalla de Call of Duty: WWII donde aparece un campo de concentración vacío en elq ue solo aparecen las camas, como ocurría en Wolfenstein: The New Order. 
Existe una clara desconexión, por tanto, entre el pasado recordado y representado por el videojuego y la historia documentada. La inclusión del Holocausto en estos dos ejemplos sigue la misma senda hasta aquí defendida: la existencia de una memoria estética que ha sustituido, en los medios de comunicación de masas, a la historia. Ya que otra de las razones que explican el formato escogido por Wolfenstein: The New Order y Call of Duty WWII para representar el genocidio judío se encuentran en la memoria estética del mismo. Existen, en la cultura mediática de masas occidentales, dos mediaciones maestras acerca de este hecho que son ineludibles para representar el Holocausto en la pantalla: la serie de televisión Holocausto (Gerald Green, 1978) y La lista de Schindler (Steven Spielberg, 1993). Tal y como explica Sánchez-Biosca para el primer caso:

Aun cuando el proceso es muy complejo, lo cierto es que el docudrama televisivo Holocausto (1978) dio forma narrativa, plástica y argumentativa a una tendencia que se había puesto probablemente en marcha en los Estados Unidos con el filme El diario de Anna Frank (1959) y que logró asentar un modelo de larga duración en la memoria del Holocausto, justo el mismo año en que Jimmy Carter creaba una comisión encabezada por Ellie Wiesel destinada a preparar un memoria que acabaría siendo el United States Holocaust Museum de Washington (2007: 155).

El modelo erigido por la serie de televisión fue recogido, y actualizado, por Spielberg en su película, la cual ha sido vista en más de 675 millones de hogares. Un dato que la ha convertido en la producción estadounidense con mayor audiencia para un programa no deportivo (2006: 151) ${ }^{11}$. De acuerdo a Shlomo Sand la televisión, la imagen mediática en general, se ha convertido en la principal fuente de conocimiento del ciudadano medio sobre el Holocausto y los horrores perpetrados por el régimen nazi (2003: 352). Esta situación ha provocado el nacimiento de una memoria estética acerca del acontecimiento que debe ser reproducida literalmente para asegurar la semejanza con lo ocurrido. De acuerdo a Sand esta reproducción se amplía con un ritmo de dos películas u obras mediáticas al año (2003: 339), una producción abultada que no ha logrado profundizar ni mejorar el conocimiento que se tiene sobre el suceso, sino que tan solo ha logrado perpetuarlo estéticamente en los medios de comunicación de masas (2003: 347). Un hecho al que viene a sumarse Call of Duty WWII al reproducir, de nuevo, todos los retrolugares contenidos en la mediación maestra de La lista de Schindler:

La representación de los judíos como polvo de seres humanos, no sólo en el exterminio sino también en la operación de salvamento, parece corresponderse con la nueva concepción que el realizador-productor todopoderoso de

11 A fecha de 2006.

Pasado y Memoria. Revista de Historia Contemporánea, 20, 2020, pp. 277-301 
Hollywood tiene del martirio judío. La condición evidente para este modo de representación era que todos los perseguidos fueran exclusivamente judíos (en la película no aparecen otras víctimas) y que todos fueran buenos y justos (incluidos los policías del gueto, que se comportan como monaguillos) (2003: 354).

En el videojuego los judíos están tan representados como polvo que éstos no llegan ni tan siquiera a verse, sin embargo aparecen como los únicos perseguidos, el objetivo principal del nazismo. Otro de los retrolugares impuestos por la serie de televisión Holocausto. De acuerdo a Sand el programa televisivo consiguió cambiar la percepción acerca del nazismo y representarlo como exclusivamente antijudío (2003: 335). En el videojuego este retrolugar se antoja transparente como el cristal. No existe, en ningún título ambientado en la Segunda Guerra Mundial, ninguna mención al exterminio de otras comunidades que no sean la judía.

Esta tímida representación del genocidio en Call of Dutty WWII guarda entonces relación con las características referidas a la memoria, a la memoria estética y a los retrolugares como principales culpables de la reproducción de mensajes e imágenes en los medios de comunicación de masas con un doble objetivo: asemejarse a mediaciones maestras anteriores que logren reforzar la pretensión de literalidad histórica del producto y perpetuar una memoria útil, una americanización del Holocausto, como bien mencionaba Sánchez-Biosca, que sirva para enseñar los valores tradicionales estadounidenses (2006: 139).

\section{Conclusión}

Esta división entre la memoria estética y la historia no sólo se encuentra en este tipo de títulos digitales, se trata de una característica del capitalismo artístico, así denominado por el sociólogo Gilles Lipovetsky y Jean Serroy, historiador del cine, quienes afirmaban que "lo cultural (los estilos de vida) se ha liberado de las costumbres y tradiciones en nombre del principio de libertad individual" (2015: 329). El pasado de la cultura de masas característico del capitalismo artístico o estético se ha desconectado de la historia, la costumbre, la cultura y la tradición y ha abrazado lo económico, la diversión y la seducción. Esta nueva cultura, e historia de masas, "trata todos los temas como entretenimiento, lo transforma todo, la cultura, la información la política en espectáculo de show-business, pensando en placeres y emociones que se renuevan sin cesar" (2015: 225). Los responsables de estos videojuegos confirman esta idea. Aleksander Grøndal, productor ejecutivo de la empresa DICE, afirmó en su perfil público de Twitter que: "We will always put fun over authentic" (Arif, 2018). No es el único caso, otros muchos responsables de títulos históricos han afirmado que sus obras deben entenderse desde tres ángulos: el económico, la diversión y la seducción (Venegas Ramos, 2018). 
Queda patente entonces la reificación del pasado en el medio del videojuego y la creación de una memoria estética que se reproduce mediante diferencias marginales, característica fundamental de la cultura y el arte del capitalismo estético: "el capitalismo artístico y su orden mediático-publicitario es un sistema que produce «diversidad homogénea», repetición en la diferencia, lo mismo en la pluralidad" (Lipovetsky y Serroy, 2015: 43) que ha encontrado en el pasado una fuente inagotable de espectáculo, tal y como afirmaba Traverso:

Es evidente que hay representaciones del pasado fabricadas por los medios y la industria cultural, lugares privilegiados de una verdadera reificación de la historia, transformada así en un inagotable reservorio de imágenes accesibles y consumibles en cualquier momento (2013: 286).

Este pasado transformado en memoria estética reificada, convertido en espectáculo de masas y reproducido constantemente en diferentes medios ha logrado crear un ayer épico y estético en la cultura de masas del capitalismo artístico cuya fuente principal es el discurso memorístico proveniente de las instituciones de Estado, de cuyas fuentes, recursos y ayudas se nutre. La novedad radical de este presupuesto es su alcance. Los videojuegos de contenido histórico aquí trazados tienen una clara pretensión universalista, así lo demuestran las altísimas cifras de venta de la saga Call of Duty en países de Oriente Medio o la India (Shaw, 2013; Sisler, 2013). O la necesidad, de algunas empresas, de narrar episodios históricos ajenos a sus memorias colectivas, e incluso oficiales, para alcanzar esa pretendida universalidad: es el caso del título francés Steel Division: Normandy 44 (Eugen Systems, 2017). Sus desarrolladores, durante una entrevista, reconocieron la necesidad de representar un acontecimiento reconocido por el público mayoritario: el desembarco de Normandía, con la intención de obtener réditos económicos y ser capaces de seducir a un público global (Wilson, 2017). Una situación que evidencia la afirmación de Gilles Lipovetsky: "Este arte híbrido se ha convertido en «arte de masas», accesible sin esfuerzo o sin estudios formales y en busca de un público amplísimo, potencialmente planetario. Y, para ser más concretos todavía, en arte de consumo de masas" (2015: 57). Es necesario convencerse, ante esta situación, que "el capitalismo artístico no es sólo productor de bienes y servicios comerciales, es al mismo tiempo el lugar principal de la producción simbólica, el creador de un imaginario social, de una ideología, de mitologías significativas" (2015: 104) y, podríamos añadir, de una visión homogénea y con pretensión universalista del pasado.

Hemos pretendido dejar patente en este artículo la existencia de una memoria estética en el videojuego histórico, potencialmente extensible al resto de producciones culturales o artísticas ambientadas en el pasado y dirigidas a los medios de comunicación de masas. Para demostrarlo hemos acudido a los videojuegos ambientados en la Segunda Guerra Mundial y en cómo éstos han generado una memoria del ayer que nada tiene que ver con la historia y cuyas 
modificaciones son entendidas como inadecuadas no por su falta de historicidad sino por su falta de correspondencia con la memoria estética generada. Una situación que ha tenido como causa la desconexión entre la historia y el relato memorístico reificado producido por el capitalismo estético como consecuencia de la conversión de la cultura en espectáculo dirigido por tres vectores: lo económico, lo divertido y lo seductor.

\section{Bibliografía}

Alexander, J. (2018). Total War: Rome 2 dev says it won't remove female generals from the game. Polygon. Consultado el 19 de julio de 2019, desde https://www.polygon. com/2018/9/26/17902302/total-war-rome-2-developer-response-female-generals-historical-accuracy

Andersen, A. (2018).Creating Call of Duty WWII's Historic Sound - an in-depth interview with Dave Swenson. A Sound Effect. Consultado el 22 de junio de 2019, desde https://www.asoundeffect.com/call-duty-wwii-sound/

Anderson, C. A., Gentile, D. A., y Buckley, K. E. (2007). Violent video game effects on children and adolescents: Theory, research, and public policy. Oxford University Press.

Atwood, K. J. (2011). Women Heroes of World War II: 26 Stories of Espionage, Sabotage, Resistance, and Rescue. Chicago Review Press.

Bauman, A. (2013). Fierce Combat and Nasty Villains in Wolfenstein: The New Order. Gamespot. Consultado el 10 de febrero de 2018 desde https://www.gamespot.com/ videos/fierce-combat-and-nasty-villains-in-wolfenstein-th/2300-6408067/

Brown, F. (2018). Kassandra is Assassin's Creed Odyssey's main hero, but only in the book. Rock Paper Shotgun. Consultado el 19 de julio de 2019, desde https://www. rockpapershotgun.com/2018/06/22/assassins-creed-odyssey-main-character/

Chapman, A., y Linderoth, J. (2015). Exploring the limits of play: A case study of representations of Nazism in games. En The Dark Side of Game Play (pp. 137-153). Routledge.

Clover, C. (2016). Black Wind, White Snow: The Rise of Russia's New Nationalism. Yale University Press, Cambridge.

Cole, W. (1992). Women Pilots of World War II. University of Utah Press.

David Z., Daniel K., Y Paul C. (2018). «Behavioural realism and the activation of aggressive concepts in violent video games». Entertainment Computing, Vol. 24, No 21. Consultado en University of York. No evidence to support link between violent video games and behavior. ScienceDaily. Consultado el 24 de julio de 2018 desde www.sciencedaily.com/releases/2018/01/180116131317.htm

Dower, J. (2012). Culturas de guerra: Pearl Harbor, Hiroshima, 11-S, Iraq. Pasado \& Presente, Barcelona.

Faludi, S. (2009). La pesadilla terrorista. Miedo y fantasía en Estados Unidos después del 11S. Anagrama, Barcelona.

Farokhmanesh, M. (2018). Battlefield V fans who failed history are mad that the game has women in it. The Verge. Consultado el 28 de octubre de 2018 desde https://web.archive.org/web/20180530140326/https://www.theverge.com/2018/5/24/17388414/ battlefield-v-fans-game-women-world-war-2-history. 
Halsall, C. (2012). Women of Intelligence: Winning the Second World War with Air Photos. Spellmount.

Hoffman, J. (2014). Major new game set at Nazi concentration camp is top seller. The Times of Israel. Consultado el 10 de febrero de 2018 desde https://www.timesofisrael. com/major-new-game-set-at-nazi-concentration-camp-is-top-seller/

Huntemann, N. B., \& Payne, M. T. (Eds.). (2009). Joystick soldiers: The politics of play in military video games. Routledge, Nueva York.

Jung, B. (2010). Narrating Violence in Post-9/11 Action Cinema: Terrorist Narratives, Cinematic Narration, and Referentiality. Springer VS, Berlín.

Kühn, S., Kugler, D. T., Schmalen, K., Weichenberger, M., Witt, C., y Gallinat, J. (2018). «Does playing violent video games cause aggression? A longitudinal intervention study». Molecular psychiatry, Vol. 1.

Lenoir, T., y Caldwell, L. (2018). The military-entertainment complex. Harvard University Press, Cambridge.

Lipovetsky, G., y Serroy, J. (2015). La estetización del mundo: vivir en la época del capitalismo artístico, Barcelona, Anagrama.

Martin, M. (2018). Battlefield 5 has women in it. If that bothers you, please, piss off. VG24/7. Consultado el 28 de octubre de 2018 desde https://www.vg247. com/2018/05/24/battlefield-5-women-bothers-please-piss-off/

Massanari, A. (2017). \#Gamergate and The Fappening: How Reddit's algorithm, governance, and culture support toxic technocultures. New Media \& Society. 19(3), 329-346. O Chess, S., y

Mead, C. (2013). War play: Video games and the future of armed conflict. Houghton Mifflin Harcourt, Nueva York.

Mortensen, T. E. (2016). Anger, Fear, and G ames: The Long Event of \#GamerGate. Games and Culture.

Paget, D., y Lipkin, S. N. (2009). "Movie-of-the-Week" docudrama, "historical-event" television, and the Steven Spielberg series Band of Brothers. New Review of Film and Television Studies, 7(1), pp. 93-107.

Parker, L. (2017). The history behind the history of Call of Duty: WW2. Gamespot. Consultado el 23 de julio de 2019, desde https://www.gamespot.com/articles/theweight-of-history-exploring-the-real-life-insp/1100-6453656/

Pearson, J. (2016). 'Battlefield 1' Misses Out On the Stories of Black Soldiers In WWI. Vice. Consultado el 22 de julio de 2019, desde https://www.vice.com/en_us/article/ jpgkp3/battlefield-1-misses-out-on-the-stories-of-black-soldiers-in-wwi

Plunkett, L. (2018). Oh No, There Are Women In Battlefield V. Kotaku. Consultado el 28 de octubre de 2018 desde https://web.archive.org/web/20180530135530/https:// kotaku.com/oh-no-there-are-women-in-battlefield-v-1826275455

Rachman, G. (2018). Donald Trump leads a global revival of nationalism. Financial Times. Consultado el 22 de julio de 2019, desde https://www.ft.com/content/59a37a387857-11e8-8e67-1ela0846c475

Ramsay, D. (2015). American Media and the Memory of World War II. Routledge, Nueva York. Redacción de EDGE. (2011). "The making of: Medal of Honor». Edge Magazine. Consultado el 27 de julio de 2017, desde «https://web.archive.org/web/20120527113621/ http://www.edge-online.com/features/making-medal-honor».

Pasado y Memoria. Revista de Historia Contemporánea, 20, 2020, pp. 277-301 
Rosenberg, A. (2017). Call of Duty: WWII won't ignore the Holocaust anymore. Mashable. Consultado el 13 de febrero de 2018 desde https://mashable.com/2017/04/26/ call-of-duty-wwii-holocaust-interview/\#fc3CjjxTAiqV

Schrader, H. (2006). Sisters in Arms: British \& American Women Pilots During World War II. Casemate Publishers.

Arif, S. (2018). Battlefield V Producer Says DICE Will 'Always Put Fun Over Authentic'. IGN. Consultado el 28 de julio de 2019, desde https://www.ign.com/ articles/2018/05/24/battlefield-v-producer-says-dice-will-always-put-fun-overauthentic

Salvati, A. J., y Bullinger, J. M. (2013) "Selective Authenticity and the Playable Past", en M. W. Kapell y A. B. Elliott (Coords.), en K. M. Wilhelm y A. B. R., Elliott (Coords.): Playing with the past: Digital games and the simulation of history, Nueva York, Palgrave MacMillan.

Sand, S. (2001). El siglo XX en pantalla: cien años a través del cine, Barcelona, Crítica.

Sánchez-Biosca, V. (2007). Cine de historia, cine de memoria: la representación y sus límites. Madrid, Cátedra.

Shaw A. (2015). A Conspiracy of Fishes, or, How We Learned to Stop Worrying About \#GamerGate and Embrace Hegemonic Masculinity. Journal of Broadcasting \& Electronic Media. Volumen 59, 2015 - Número 1.

Shaw, A. (2013). How Do You Say Gamer in Hindi?: Exploratory research on the Indian digital game industry and culture. En Gaming Globally (pp. 183-201). Palgrave Macmillan, New York, pp. 183-184.

Šisler, V. (2013). Video game development in the Middle East: Iran, the Arab world, and beyond. En Gaming Globally (pp. 251-271). Palgrave Macmillan, New York., p. 262.

Sottek, T. C. (2018). After 16 years of war, Battlefield V is a turning point. The Verge. Consultado el 28 de octubre de 2018 desde https://www.theverge. com/2018/6/29/17518286/battlefield-v-grand-operations-pc-ps4-xbox-one

Stahl, R. (2009). Militainment, Inc.: War, media, and popular culture. Routledge, Nueva York.

Suid, L. H. (2002). Guts and Glory: The making of the american military image in film. The University Press of Kentucky, Lexington

Sutherland, C. (2011). Nationalism in the Twenty-First Century. Challenges and Responses. Red Globe Press, Nueva York.

Tamir, Y. (2019). Why Nationalism. Princeton University Press, Princeton.

Thomas Payne, M. (2016). Playing War: Military Video Games After 9/11. New York University Press, Nueva York.

Traverso, E. (2011). El Pasado, instrucciones de uso: historia, memoria, politica. Buenos Aires, Prometeo Libros.

Venegas Ramos, A. (2018). «Entre el cine y el videojuego: ética y estética en las producciones sobre la II Guerra Mundial». Videojuegos e Historia: entre el ocio y la cultura. Colección Historia y Videojuegos No5. Editum, Universidad de Murcia.

Venegas Ramos, A. (2018). Realidad política y responsabilidad del autor en el videojuego actual. Presura. Consultado el 28 de julio de 2019, desde http://www.presura. es/2018/06/25/politica-y-responsabilidad-del-autor-en-el-videojuego/ 
Venegas Ramos, A. (2019). Los enemigos del videojuego. Anaitgames. Consultado el 23 de junio de 2019, desde https://www.anaitgames.com/articulos/los-enemigos-delvideojuego

Westwell, G. (2014). Parallel lines: post-9/11 American cinema. Columbia University Press, Wallflower Press, Nueva York.

Wilson, J. (2017). Steel Division: Normandy 44 is Paradox Interactive's grand entrance into tactical combat. VentureBeat. Consultado el 15 de febrero de 2018 desde https:// venturebeat.com/2017/03/01/steel-division-normandy-44-is-paradox-interactivesgrand-entrance-into-real-time-tactical-combat/ 